\title{
Effect of dexamethasone in combination with caudal analgesia on postoperative pain control in day-case paediatric orchiopexy
}

\author{
J.-Y. Hong ${ }^{1}$, S. W. $\operatorname{Han}^{2}$, W. O. Kim ${ }^{1}$, E. J. Kim ${ }^{1}$ and H. K. Kil ${ }^{1 *}$ \\ ${ }^{1}$ Department of Anesthesiology and Pain Medicine, Anesthesia and Pain Research Institute and ${ }^{2}$ Department of Urology, Urological \\ Science Institute, Yonsei University College of Medicine, Severance Hospital, 250 Seongsanno, Seodaemun-gu, 120-752 Seoul, \\ Republic of Korea \\ *Corresponding author. E-mail: hkkil@yuhs.ac; jenyhongg@hanmail.net
}

\section{Key points}

- I.V. dexamethasone $0.5 \mathrm{mg}$ $\mathrm{kg}^{-1}$ after induction of anaesthesia provided better postoperative analgesia than placebo after paediatric orchiopexy.

- Requirements for rescue analgesia in post-anaesthetic care unit were lower and time to request postoperative analgesia were longer after i.v. dexamethasone.

- The incidence of adverse effects was low.

- Postoperative pain is an important problem that may be undertreated in the paediatric population, especially in children undergoing day-case surgery.
Background. Dexamethasone has a powerful anti-inflammatory action and has demonstrated reduced morbidity after surgery. The aim of this study was to examine the effects of a single i.v. dose of dexamethasone in combination with caudal block on postoperative analgesia in children.

Methods. Seventy-seven children (aged 1-5 yr) undergoing day-case orchiopexy were included in this prospective, randomized, double-blinded study at a single university hospital. After inhalation induction of general anaesthesia, children received either dexamethasone $0.5 \mathrm{mg} \mathrm{kg}^{-1}$ (maximum $\left.10 \mathrm{mg}\right)(n=39)$ or the same volume of saline $(n=38)$ i.v. A caudal anaesthetic block was then performed using $1.5 \mathrm{ml} \mathrm{kg}^{-1}$ of ropivacaine $0.15 \%$ in all patients. After surgery, rescue analgesic consumption, pain scores, and adverse effects were evaluated for $24 \mathrm{~h}$.

Results. Significantly, fewer patients in the dexamethasone group required fentanyl for rescue analgesia $(7.9 \%$ vs $38.5 \%)$ in the post-anaesthetic care unit or acetaminophen ( $23.7 \%$ vs $64.1 \%)$ after discharge compared with the control group. The time to first administration of oral acetaminophen was significantly longer in the dexamethasone group (646 vs $430 \mathrm{~min}$ ). Postoperative pain scores were lower in the dexamethasone group and the incidence of adverse effects was similar in both groups.

Conclusions. Intravenous dexamethasone $0.5 \mathrm{mg} \mathrm{kg}^{-1}$ in combination with a caudal block augmented the intensity and duration of postoperative analgesia without adverse effects in children undergoing day-case paediatric orchiopexy.

Trial registration: ClinicalTrials.gov. The number of registration: NCT01041378.

Keywords: anaesthesia, caudal; anaesthesia recovery period; analgesia, postoperative; dexamethasone; surgery, day case; surgery, urological, paediatric; orchiopexy

Accepted for publication: 18 May 2010
A caudal block is a popular reliable and safe technique for paediatric pain management after infraumbilical surgical procedures. However, in a significant proportion of patients, despite good initial analgesia from a caudal blockade with local anaesthetic, moderate or severe pain develops as the block resolves. ${ }^{1}{ }^{2}$ The addition of various drugs such as opioids, ketamine, clonidine, or dexmedetomidine to local anaesthetics has been used to improve or prolong caudal analgesia, but their use has been limited by unacceptable adverse effects in children undergoing day-case surgery. ${ }^{3-7}$

Dexamethasone, a corticosteroid with strong antiinflammatory effects, provides postoperative analgesia and has shown improvement in morbidity such as nausea, vomiting, fever, and delayed oral intake in children. ${ }^{8}{ }^{9}$ However, there are no few data in children undergoing urological procedures.
Therefore, we performed this prospective randomized double-blind study to examine the effects of single intraoperative dexamethasone combined with a caudal block on recovery in children undergoing day-case orchiopexy.

\section{Methods}

The IRB of our institution approved this study, and parental consent was obtained for each case. Eighty ASA status I unpremedicated children, aged 1 to $5 \mathrm{yr}(\leq 20 \mathrm{~kg})$ and undergoing day-case unilateral orchiopexy, were enrolled in this prospective, randomized, and double-blind study. Patients were excluded from the study if they had a contraindication for caudal block including a hypersensitivity to any local anaesthetics, bleeding diathesis, infections at the puncture 
sites, or pre-existing neurological disease. Each patient was randomly assigned to one of the two groups by following a computer-generated randomization table. On the day of the pre-anaesthetic visit, parents were taught to perform their role in the study and the use of visual analogue pain scores (VAS, $0=$ 'no pain' and $10=$ 'the worst imaginable pain') after discharge.

Standard monitoring was conducted and anaesthesia was induced with of sevoflurane $8 \%$ in oxygen by an anaesthetist who was unaware of the group allocation. After i.v. access was secured, tracheal intubation was performed after the administration of $0.5 \mathrm{mg} \mathrm{kg}^{-1}$ of atracurium and mechanically controlled ventilation was used to maintain end-tidal carbon dioxide at 35 (SD 5) $\mathrm{mm} \mathrm{Hg}$. Then, children received either dexamethasone $0.5 \mathrm{mg} \mathrm{kg}^{-1}$ (maximum $10 \mathrm{mg}$ ) (dexamethasone sodium phosphate $5 \mathrm{mg} \mathrm{ml}^{-1}$, Yuhan Co., Seoul, Korea) or the same volume of saline i.v. ( $n=40$ in each group). All study drugs were given by an anaesthesia nurse who did not participate in subsequent management.

After induction of anaesthesia, caudal block was performed using a $5 \mathrm{~cm}$ short bevelled $22 \mathrm{G}$ caudal needle after measuring the optimal angle with ultrasonography (LOGIQe, GE Healthcare, Wauwatosa, WI, USA) in the lateral decubitus position. ${ }^{10}$ After identifying the space using the loss of resistance technique with saline, children received $1.5 \mathrm{ml} \mathrm{kg}^{-1}$ ropivacaine $0.15 \%$ (maximum volume, $20 \mathrm{ml}$ ) freshly prepared.

Surgery was allowed to begin 10 min after performing the block. The same urologist performed all surgical procedures. End-tidal sevoflurane concentration was adjusted according to clinical signs (arterial pressure or heart rate within $20 \%$ of baseline). After emergence from anaesthesia, patients were managed by an observer blinded to group allocation in the post-anaesthetic care unit (PACU). Postoperative pain was assessed at the end of surgery, 30, 60, 120, and 180 min after surgery using the Children's Hospital of Eastern Ontario Pain Scale (CHEOPS, 0-10) ${ }^{11}$ and Faces Legs Activity Cry Consolability tool (FLACC, 0-10). ${ }^{12}$ I.V. fentanyl $0.5 \mu \mathrm{g}$ $\mathrm{kg}^{-1}$ was administered as rescue analgesia if two coupled observations separated by a 5 min waiting period yielded both CHEOPS and FLACC $\geq 5$. Motor block was assessed with a modified Bromage ${ }^{13}$ score (0, no motor block; 1 , able to move legs; 2 , unable to move legs). Postoperative sedation was evaluated using the eight-point modified Ramsay Sedation Scale. ${ }^{14}$

Discharge criteria included clear consciousness, stability of vital signs, ability to tolerate oral fluids and void, age-appropriate level of ambulation, and absence of sideeffects. Analgesia after discharge was provided with oral acetaminophen $(100 \mathrm{mg}$ in $5 \mathrm{ml}$ ). The time to first supplemental oral acetaminophen demand (first acetaminophen time) was defined as the time from the end of surgery to the first registration of a VAS $(0-10) \geq 5$ by parent's observation. ${ }^{15}$ Twenty-four hours after surgery, reports of delayed side-effects and demands for rescue acetaminophen from the child were gathered from parents via a telephone interview. The interviewer, who was blinded to the treatment group, documented these data with the medical records. A questionnaire was also supplied to assess the parent's satisfaction on a four-point Likert scale (1, excellent; 2, good; 3, fair; 4, poor). This scale has been validated to score patients' satisfaction with anaesthetic technique and postoperative pain relief. ${ }^{16}$

Sample size calculation was based on our previous data, ${ }^{17}$ in which we found that mean (SD) to first analgesia in children who received caudal analgesia for orchiopexy using $1.5 \mathrm{ml}$ $\mathrm{kg}^{-1}$ ropivacaine $0.15 \%$ was 554.5 (114.6) min after surgery. We calculated that 36 patients in each group would be required to show a $20 \%$ difference in this time $(\alpha=0.05, \beta=0.1)$. A total of 80 patients were enrolled for potential protocol omissions. Data distribution was assessed for normality using the Kolmogorov-Smirnov and ShapiroWilk tests. Differences between the groups were analysed using Student's t-test, Mann-Whitney rank sum test, $\chi^{2}$ test, and Fisher's exact test when appropriate. A repeatedmeasured analysis of variance with the Bonferroni correction was performed to test for inter-group difference in changes of the arterial pressure, heart rate, and pain scores measured at the designated time points. A P-value of $<0.05$ was considered significant.

\section{Results}

Eighty patients were recruited to the study but three patients were excluded because of intraoperative administration of fentanyl or midazolam, so data from 77 patients were analysed. There were no significant differences between the two groups with regard to their age, weight, height, duration of surgery, and intraoperative fluid administration (Table 1). There was no failure of caudal block in any patient.

The incidence of rescue fentanyl in the PACU and rescue oral acetaminophen after discharge was significantly lower in children who received dexamethasone compared with those who received saline (Table 2). Eleven of the 39 in the control group and three of the 38 in the dexamethasone group received both fentanyl rescue in PACU and oral acetaminophen after discharge. The time to first oral acetaminophen administration was significantly longer in the dexamethasone group compared with the control group. Pain scores using CHEOPS and FLACC assessed at the PACU

Table 1 Mean (range) or mean (SD) patient data and intraoperative characteristics. There was no difference in variables between the groups

\begin{tabular}{lcc}
\hline & $\begin{array}{l}\text { Control group } \\
(\boldsymbol{n}=\mathbf{3 9 )}\end{array}$ & $\begin{array}{l}\text { Dexamethasone } \\
\text { group }(\boldsymbol{n}=\mathbf{3 8})\end{array}$ \\
\hline Age (months) & $21.8(12-68)$ & $20.0(13-57)$ \\
Weight $(\mathrm{kg})$ & $12.1(2.7)$ & $11.9(2.8)$ \\
Height $(\mathrm{cm})$ & $84.8(12.1)$ & $83.8(12.4)$ \\
Duration of surgery $(\mathrm{min})$ & $38.2(13.2)$ & $38.1(12.7)$ \\
Fluid administered $(\mathrm{ml})$ & $114.5(54.2)$ & $103.5(39.2)$ \\
\hline
\end{tabular}


Table 2 Postoperative rescue analgesics expressed as proportion (\%) or mean (sD). ${ }^{*} P<0.01 ;{ }^{\dagger} P=0.012$

\begin{tabular}{lll}
\hline & $\begin{array}{l}\text { Control group } \\
(\boldsymbol{n}=39)\end{array}$ & $\begin{array}{l}\text { Dexamethasone } \\
\text { group }(\boldsymbol{n}=\mathbf{3 8})\end{array}$ \\
\hline $\begin{array}{l}\text { Rescue fentanyl at PACU } \\
\begin{array}{l}\text { Rescue acetaminophen } \\
\text { after discharge }\end{array}\end{array}$ & $\begin{array}{l}25 / 39(38.5 \%) \\
\begin{array}{l}\text { Rescue fentanyl+oral } \\
\text { acetaminophen }\end{array}\end{array}$ & $\begin{array}{l}3 / 38^{*}(7.9 \%) \\
9 / 35^{*}(25.7 \%)\end{array}$ \\
$\begin{array}{l}\text { Time to first } \\
\text { acetaminophen (min) }\end{array}$ & $430(205)$ & $648^{*}(7.9 \%)$ \\
\hline
\end{tabular}

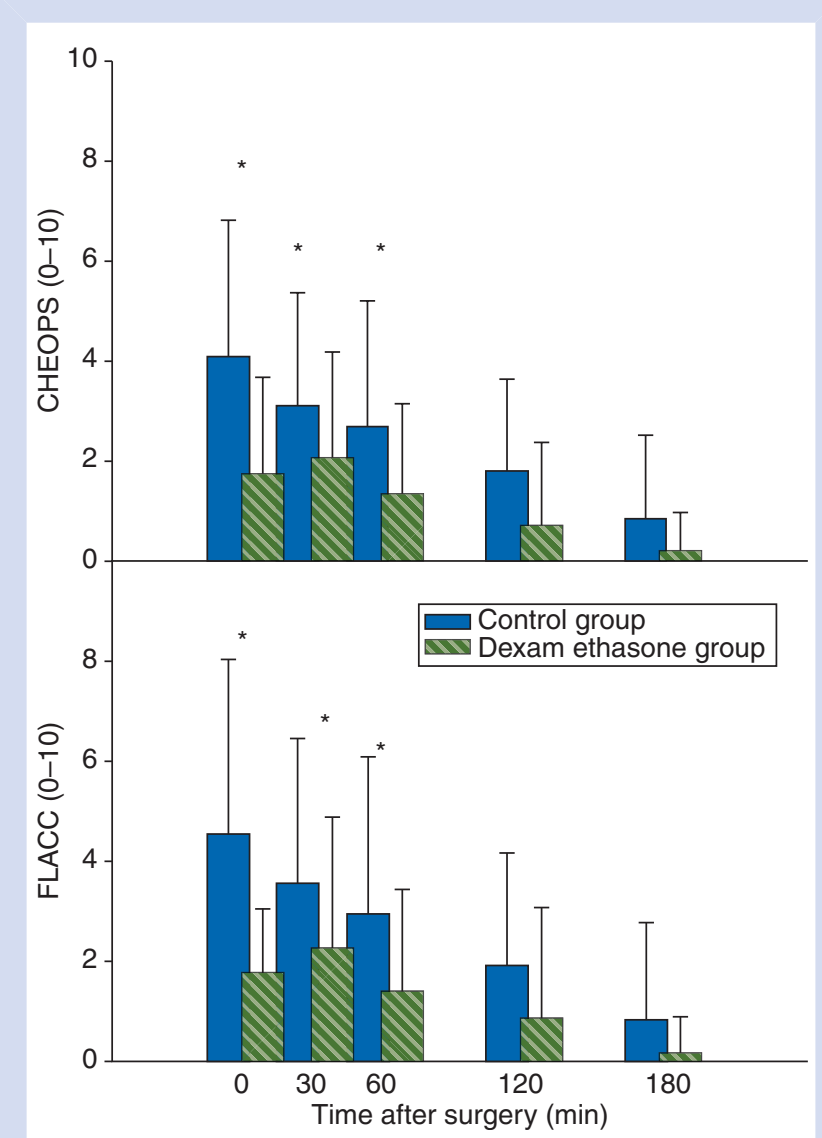

Fig 1 Postoperative pain scores. Pain scores using CHEOPS and FLACC assessed at the PACU were significantly lower $1 \mathrm{~h}$ after surgery in the dexamethasone group than in the control group.

were significantly lower in the dexamethasone group than in the control group (Fig. 1). Time to first administration of acetaminophen time is displayed as a Kaplan-Meier curve with censoring of those patients who received fentanyl in PACU displayed (Fig. 2). The Kaplan-Meier survival analysis with log-rank test (Mantel-Cox) showed a significant difference between the two groups $(P<0.001)$.

There were no significant differences in the incidence of adverse effects including vomiting (7.7\% vs $10.5 \%)$, sedation

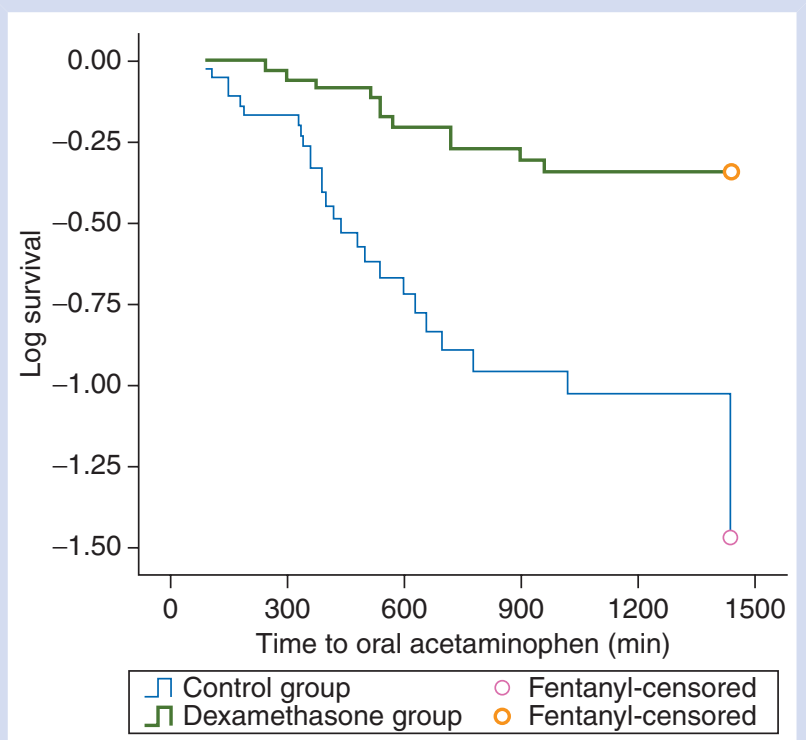

Fig 2 Kaplan-Meier curve for first oral acetaminophen time; tick marks indicate censoring for patients who had received rescue fentanyl in PACU.

( $25.6 \%$ vs $31.6 \%$ ), and shivering $(2.6 \%$ vs $0 \%$ ). All adverse effects were also well controlled by a single dose of antiemetic and meperidine. Dexamethasone-associated adverse effects were not noted in the dexamethasone group. The mean (SD) times from when the patient entered the recovery room to when they met the discharge criteria were not different $(P=0.451) ; 173.2$ (55.6) $\mathrm{min}$ in the control group and 143.3 (66.5) $\mathrm{min}$ in the dexamethasone group.

The majority of patients $(79.5 \%$ of the control group and $97.4 \%$ of the dexamethasone group) were satisfied (excellent or good) with the postoperative pain management. Patients in the dexamethasone group were more satisfied than those in the control group ( $\chi^{2}$ test, $P=0.012$ ).

\section{Discussion}

To our knowledge, this study is the first to examine the effect of an i.v. dexamethasone on pain management after paediatric urological surgery. We demonstrated that a single dose of i.v. dexamethasone $\left(0.5 \mathrm{mg} \mathrm{kg}^{-1}\right)$ in combination with a caudal block reduces postoperative pain, decreases rescue analgesic requirements, and prolongs analgesic duration compared with a caudal block alone.

We recently demonstrated that caudal analgesia with a larger volume $\left(1.5 \mathrm{ml} \mathrm{kg}^{-1}\right)$ of diluted ropivacaine $0.15 \%$ provides a longer duration than a smaller volume $(1 \mathrm{ml}$ $\mathrm{kg}^{-1}$ ) of more concentrated ropivacaine $0.225 \%$ in children undergoing day-case orchiopexy (554 vs $363 \mathrm{~min}$ ), where the total dose of ropivacaine was fixed. ${ }^{17}$ In both groups, however, the numbers of patients who required rescue oral acetaminophen after discharge were high $(50 \%$ and $76 \%$, respectively). In the present study, we demonstrated 
that i.v. dexamethasone $0.5 \mathrm{mg} \mathrm{kg}^{-1}$ in conjunction with a caudal block using the same volume $\left(1.5 \mathrm{ml} \mathrm{kg}^{-1}\right)$ and concentration $(0.15 \%)$ of ropivacaine further enhanced the analgesic duration and intensity; the number of patients who received rescue oral acetaminophen was $24 \%$ and the first acetaminophen time was $646 \mathrm{~min}$. That is, adding a single dose of i.v. dexamethasone decreased the need for analgesia after discharge by $63 \%$ and increased the duration of analgesia by up to $50 \%$ compared with patients who received a caudal block alone. Furthermore, it must be stressed that i.v. dexamethasone was not associated with adverse effects in our study.

Steroids have a powerful anti-inflammatory action ${ }^{18}$ and have demonstrated reduced pain and swelling after oral surgery, ${ }^{19}$ spinal surgery, ${ }^{20}$ and laparoscopic surgery. ${ }^{21}$ However, the exact mechanism by which dexamethasone may exert an analgesic effect is not fully understood. Systemic administration of steroids has been found to suppress tissue levels of bradykinin ${ }^{22}$ and the release of neuropeptides from nerve endings, ${ }^{23}$ both of which can enhance nociception in inflamed tissue. The established reduction in prostaglandin production might further contribute to analgesia by inhibiting the synthesis of the cyclooxygenase isoform-2 in peripheral tissues and in the central nervous system. ${ }^{24}$ They also inhibit other mediators of inflammatory hyperalgesia, for example, tumour necrosis factor- $\alpha$, interleukin-17 $\beta$, and interleukin- 6 . Thus, despite the fact that the mechanism is not yet fully understood, a reduction in pain by steroids has been supported by many studies. The clinical effects of dexamethasone are related to changes in the transcription of DNA to proteins and continue for some time after the drug is cleared from plasma. The plasma elimination half-life is only about $6 \mathrm{~h}$, and so there seems to be ongoing drug effects for a significant period of time after drug clearance from the plasma. Hval and colleagues $^{25}$ demonstrated that the analgesic effect was prolonged significantly for 3 days after administration when combined with a long-acting non-steroidal anti-inflammatory drug. Although a significant number of control patients received fentanyl rescue analgesia in the PACU, 11 of the 15 patients who received fentanyl needed further oral acetaminophen for analgesia after discharge.

Many investigators have studied the effects of systemic steroids in reducing postoperative pain and morbidity; but, there is no consensus regarding their routine use, particularly in children. Results have been conflicting; some studies demonstrating benefit and others not. ${ }^{8} 92627$ In addition, most published studies for children have been limited to the otolaryngology procedures with wide ranges of dexamethasone $\left(0.4-1.0 \mathrm{mg} \mathrm{kg}^{-1}\right.$ with maximum doses from 8 to $50 \mathrm{mg}$ ). Many studies have included children who exceeded the weight in kilograms over the maximum dose allowed; that is, there was no weight normalization of the treatment group. Differences in the dose of dexamethasone, surgical and anaesthetic techniques, intraoperative opioid use, and lack of standardization for pain scoring and management may explain in part the conflicting results reported in prior studies. Therefore, we chose a single dose of $0.5 \mathrm{mg}$ $\mathrm{kg}^{-1}$ dexamethasone for children that weighed $<20 \mathrm{~kg}$ and a maximum dose of $10 \mathrm{mg}$.

One of the major endpoints of this study, the first oral acetaminophen time, represents the parent's subjective impression of the child's pain. Because oral acetaminophen was administered after discharge, parents were frequently the sole assessor of their child's analgesic requirements. Although parental assessment of pain may be subject to bias, it has not been well studied, and we used observer VAS measures of pain to determine the need for rescue analgesic after discharge. A number of studies have provided varying levels of support for the validity of CHEOPS for the assessment of pain in postoperative children. However, as a consequence of the tight observational and recording intervals, and the numerous types of behaviour, evaluating pain is burdensome for the parent. Furthermore, Beyer and colleagues ${ }^{28}$ found that CHEOPS scores were generally very low after discharge and that over time, self-reports of pain worsened. Thus, CHEOPS may be valid only during the immediate postoperative period. Tarbell and colleagues ${ }^{29}$ also noted that the strong correlation between CHEOPS and observer VAS measures of pain may mean that it is more practical to use observer VAS.

One of the primary benefits of dexamethasone, as reported in previous studies, has been the decrease in postoperative nausea and vomiting. Dexamethasone may exert an antiemetic action via prostaglandin antagonism, serotonin inhibition in the gut, and release of endorphins. In this study, we found no difference and the incidences of vomiting were very low in both groups. This may be related to the lack of administration of intraoperative opioids and combined pain management with caudal analgesia.

The risk to patients of a single dose of dexamethasone appears to be minimal. We did not measure the plasma concentrations of dexamethasone, cortisol, or any other parameters associated with i.v. dexamethasone because invasive blood samplings for hormonal assays and long-term follow-ups were not applicable especially in children undergoing day-case minor infraumbilical surgeries. However, most previous studies have demonstrated that for paediatric and adult patients undergoing surgical procedures, a perioperative single-dose administration of dexamethasone is not associated with a significant increase in the incidence of adverse effects. ${ }^{8} 92627$ In addition, we found no reports in the literature of complications from the use of a single dose of i.v. dexamethasone during paediatric surgery. Therefore, we suggest that i.v. single administration of dexamethasone is an easy, simple, safe, and effective adjuvant analgesic method for relieving paediatric postoperative pain and exhibits highly significant fentanyl-sparing effects. In addition, the cost of dexamethasone is relatively low, which makes routine use reasonable.

Therefore, we conclude that an i.v. dexamethasone in combination with a caudal block with ropivacaine reduces the intensity of postoperative pain and prolongs analgesic duration after paediatric orchiopexy. A single 
dose of $0.5 \mathrm{mg} \mathrm{kg}^{-1}$ (maximum $20 \mathrm{mg}$ ) was not associated with adverse effects.

\section{Conflict of interest}

None declared.

\section{References}

1 Silvani P, Camporesi A, Agostino MR, Salvo I. Caudal anesthesia in paediatrics: an update. Minerva Anestesiol 2006; 72: 453-9

2 Wolf AR. Tears at bedtime: a pitfall of extending paediatric day-case surgery without extending analgesia. $\mathrm{Br} J$ Anaesth 1999; 82: 319-20

3 Wolf AR, Hughes D, Wade A, Mather SJ, Prys-Roberts C. Postoperative analgesia after paediatric orchidopexy: evaluation of a bupivacaine-morphine mixture. $\mathrm{Br} J$ Anaesth 1990; 64: 430-5

4 Constant I, Gall O, Gouyet L, Chauvin M, Murat I. Addition of clonidine or fentanyl to local anaesthetics prolongs the duration of surgical analgesia after single shot caudal block in children. $\mathrm{Br} J$ Anaesth 1998; 80: 294-8

5 Semple D, Findlow D, Aldridge LM, Doyle E. The optimal dose of ketamine for caudal epidural blockade in children. Anaesthesia 1996; 51: 1170-2

6 Saadawy I, Boker A, Elshahawy MA et al. Effect of dexmedetomidine on the characteristics of bupivacaine in a caudal block in paediatrics. Acta Anaesthesiol Scand 2009; 53: 251-6

7 Ansermino M, Basu R, Vandebeek C, Montgomery C. Nonopioid additives to local anaesthetics for caudal blockade in children: a systematic review. Paediatr Anaesth 2003; 13: 561-73

8 Mohamed SK, Ibraheem AS, Abdelraheem MG. Preoperative intravenous dexamethasone combined with glossopharyngeal nerve block: role in paediatric postoperative analgesia following tonsillectomy. Eur Arch Otorhinolaryngol 2009; 266: 1815-9

9 Hanasono MM, Lalakea ML, Mikulec AA, Shepard KG, Wellis V, Messner AH. Perioperative steroids in tonsillectomy using electrocautery and sharp dissection techniques. Arch Otolaryngol Head Neck Surg 2004; 130: 917-21

10 Park JH, Koo BN, Kim JY, Cho JE, Kim WO, Kil HK. Determination of the optimal angle for needle insertion during caudal block in children using ultrasound imaging. Anaesthesia 2006; 61: 946-9

11 Crellin D, Sullivan TP, Babl FE, O'Sullivan R, Hutchinson A. Analysis of the validation of existing behavioral pain and distress scales for use in the procedural setting. Paediatr Anaesth 2007; 17: 720-33

12 Willis MH, Merkel SI, Voepel-Lewis T, Malviya S. FLACC Behavioral Pain Assessment Scale: a comparison with the child's self-report. Pediatr Nurs 2003; 29: 195-8

13 Bromage PR. Mechanism of action of extradural analgesia. $\mathrm{Br} \mathrm{J}$ Anaesth 1975; 47: 199-211

14 Agrawal D, Feldman HA, Krauss B, Waltzman ML. Bispectral index monitoring quantified depth of sedation during emergency department procedural sedation and analgesia in children. Ann Emerg Med 2004; 43: 247-55
15 Tarbell SE, Cohen IT, Marsh JL. The Toddler-Preschooler Postoperative Pain Scale: an observational scale for measuring postoperative pain in children aged $1-5$. Preliminary report. Pain 1992; 50: 273-80

16 DiTomasso RA, Willard M. The development of a patient satisfaction questionnaire in the ambulatory setting. Fam Med 1991; 23: 127-31

17 Hong JY, Han SW, Kim WO, Cho JS, Kil HK. Comparison of high volume/low concentration and low volume/high concentration of ropivacaine in caudal analgesia for paediatric orchiopexy. Anesth Analg 2009; 109: 1073-8

18 Shimmer BP, Parker KL. Adrenocorticotrophic hormone; adrenocortical steroids and their synthetic analogs: inhibitors of the synthesis and actions of adrenocortical hormones. In: Hardman JG, Limbird LE, Molinoff PB, Ruddon RW, Gilman AG, eds. Goodman and Gilman's The Pharmacological Basis of Therapeutics. Toronto: McGraw-Hill, 1996; 1459-85

19 Skjelbred P, Løkken P. Reduction of pain and swelling by a corticosteroid injected 3 hours after surgery. Eur J Clin Pharmacol 1982; 23: 141-6

20 Holte K, Kehlet H. Perioperative single-dose glucocorticoid administration: pathophysiologic effects and clinical implications. J Am Coll Surg 2002; 195: 694-712

21 Bisgaard T, Klarskov B, Kehlet H, Rosenberg J. Preoperative dexamethasone improves surgical outcome after laparoscopic cholecystectomy: a randomized double-blind placebo-controlled trial. Ann Surg 2003; 238: 651-60

22 Hargreaves KM, Costello A. Glucocorticoids suppress levels of immunoreactive bradykinin in inflamed tissue as evaluated by microdialysis probes. Clin Pharmacol Ther 1990; 48: 168-78

23 Hong D, Byers MR, Oswald RJ. Dexamethasone treatment reduces sensory neuropeptides and nerve sprouting reactions in injured teeth. Pain 1993; 55: 171-81

24 Ferreira SH, Cunha FQ, Lorenzetti BB et al. Role of lipocortin-1 in the anti-hyperalgesic actions of dexamethasone. $\mathrm{Br} J$ Pharmacol 1997; 121: 883-8

25 Hval K, Thagaard KS, Schlichting E, Raeder J. The prolonged postoperative analgesic effect when dexamethasone is added to a nonsteroidal antiinflammatory drug (rofecoxib) before breast surgery. Anesth Analg 2007; 105: 481-6

26 Vosdoganis F, Baines DB. The effect of single dose intravenous dexamethasone in tonsillectomy in children. Anaesth Intensive Care 1999; 27: 489-92

27 Giannoni C, White S, Enneking FK. Does dexamethasone with preemptive analgesia improve paediatric tonsillectomy pain? Otolaryngol Head Neck Surg 2002; 126: 307-15

28 Beyer JE, McGrath PJ, Berde CB. Discordance between self-report and behavioral pain measures in children aged 3-7 years after surgery. J Pain Symptom Manage 1990; 5: 350-6

29 Tarbell SE, Cohen IT, Marsh JL. The Toddler-Preschooler Postoperative Pain Scale: an observational scale for measuring postoperative pain in children aged 1-5. Pain 1992; 50: 273-80 